\title{
Uma bússola para navegar pelo mar aberto e desafiante do ensino de Filosofia para adolescentes
}

\section{A compass for navigating the open and challenging philosophy of teaching teengers}

\author{
Resenha de / Review of Lecionando Filosofia para adolescentes: \\ práticas pedagógicas para o Ensino Médio
}

\author{
Anderson Luis da Paixão Café \\ Servidor Público no Tribunal de Justiça do Estado da Bahia, Salvador, BA, Brasil. \\ andersoncafe2011@gmail.com - https://orcid.org/0000-0003-0653-9608
}

Recebido em 09 de maio de 2021

Aprovado em 21 de junho de 2021

Publicado em 12 de julho de 2021

RESUMO: Trata-se da resenha bibliográfica do livro Lecionando Filosofia para adolescentes: práticas pedagógicas para o Ensino Médio, no qual o professor Renato Velloso colocou à disposição de seus colegas filósofos a sua experiência de mais de quinze anos enquanto professor da disciplina de Filosofia, lecionada para adolescentes e jovens de escolas públicas e privadas no país. A obra pode ser entendida como uma verdadeira bússola que permite aos professores e às professoras de Filosofia repensar sobre as suas práticas didáticas utilizadas para difundir conhecimentos filosóficos entre jovens e adolescentes. Através de uma linguagem clara, objetiva e direta, a obra disponibiliza um amplo conjunto de informações didáticas e metodológicas que contribui para ampliar o repertório educacional dos seus leitores, fazendoos perceber o quanto a Filosofia pode ser pensada enquanto um porto seguro capaz de aliviar as dores e os sofrimentos humanos de adolescentes que estão ávidos por descobrirem-se e redescobrirem-se no mundo.

Palavras-chave: Ensino de Filosofia; Prática pedagógica; Filosofia no Ensino Médio; Adolescentes e Jovens - Ensino.

\begin{abstract}
This is the bibliographical review of the book Teaching Philosophy for teenagers: pedagogical practices for high school, in which professor Renato Velloso made available to his fellow philosophers his experience of more than fifteen years as a professor of the discipline of Philosophy taught to teenagers and young people from public and private schools in the country. The work can be understood as a true compass that allows Philosophy teachers to rethink about their didactic practices used to spread philosophical knowledge among young people and adolescents. Through a clear, objective and direct language, the work provides a wide range of didactic and methodological information that contributes to expand the educational repertoire of its readers, making them realize how much Philosophy can be thought of as a safe haven capable of alleviating human pains and sufferings of teenagers who are eager to discover and rediscover themselves in the world
\end{abstract}

Keywords: Philosophy teaching; Pedagogical practice; Philosophy in High School; Adolescents and Youth - Education. 
Atravessar mares tranquilos ou agitados; conhecidos ou desconhecidos pressupõe dos navegantes, sobretudo daqueles que estão em suas primeiras viagens, muita cautela e prudência. Desse modo, todo marinheiro que se preze não deve desvincular-se de sua bússola, que lhe orienta diante da grandeza, imensidão, beleza e profundidade das águas dos mares navegados que, assim como a vida, são marcados por mistérios, incertezas, encantos e desencantos.

Nesse sentido, a obra de autoria do professor Renato Velloso, intitulada Lecionando Filosofia para adolescentes: práticas pedagógicas para o Ensino Médio é uma verdadeira bússola que norteia o exercício profissional de professores e de professoras que, condenados à liberdade a moda do filósofo francês Jean-Paul Sartre (2014), escolheram, livremente, navegar pelo misterioso e fantástico mundo do amor à sabedoria, ensinando Filosofia aos adolescentes e jovens em escolas públicas e privadas.

Nesse livro, Velloso (2015, p. 12) coloca à disposição de seus colegas filósofos as suas vivências e experiências decorrentes de mais de quinze anos de exercício profissional no magistério de Filosofia no Ensino Médio, buscando colaborar para que os professores obtenham "êxito em suas aulas. Seja iniciante ou experiente, o profissional encontrará métodos, planejamentos, recursos, recomendações e até exercícios objetivos", de maneira a colaborar para uma maior aproximação dos alunos ao universo da Filosofia.

Percorrendo toda uma trajetória de formação acadêmica dentro do campo da Filosofia, o que Ihe permitiu legitimidade para construir a sua narrativa sobre o processo de ensinagem do pensamento filosófico para adolescentes e jovens, o professor Renato Velloso é Bacharel, Licenciado, Especialista e Mestre em Filosofia pela Universidade do Estado do Rio de Janeiro, possuindo, também, um curso específico voltado para o ensino de Filosofia para crianças, o que, aliado a sua ampla experiência profissional no magistério, atesta o seu elevado capital científico acumulado, na linguagem do sociólogo francês Pierre Bourdieu (2004), que lhe confere autoridade científica para tratar do tema nesse livro. 
Apesar de publicada, originalmente, em 2012, com uma edição revista e atualizada em 2015, o livro de Velloso (2015) desperta a atenção justamente pela escassez de literatura publicada no Brasil sobre o tema. A despeito da importância do livro, não foi encontrada nas bases de dados consultadas (Google Scholar; Scielo e Redalyc) nenhuma resenha desse livro que é uma bússola para os professores e professoras de Filosofia, sobretudo, para os novatos do campo que, quase sempre, perguntam-se por onde começar, pois essa é "a pergunta mais freqüente no início de ano letivo, senão a maior preocupação de todo professor de Filosofia, principalmente do iniciante" (VELLOSO, 2015, p. 41).

Além de possuir uma linguagem clara, objetiva e direta, a obra de Velloso (2015) destaca-se pelo didatismo que encanta e estimula os leitores. Embora o livro realize uma abordagem do ensino no campo da Filosofia, isso não impossibilita que professores e alunos de outras licenciaturas consultem-no como referência para a prática pedagógica no Ensino Médio. A obra está dividida em sete capítulos e, no final da publicação, o leitor encontrará um apêndice com sugestões de filmes, músicas e exercícios que corroboram para estimular a maior fixação de conteúdos por parte dos adolescentes.

O primeiro capítulo da obra recebeu o nome de "A importância da Filosofia". Nele, Velloso (2015) trouxe uma interessante discussão sobre o significado da disciplina no Ensino Médio, defendendo a tese de que o ensino da Filosofia é imprescindível para a formação de sujeitos críticos e reflexivos, capazes de questionar a realidade, apreendêla e transformá-la. Para tanto, Velloso (2015) mostrou os dispositivos legais que tornaram obrigatórios o ensino da Filosofia e da Sociologia no Ensino Médio (artigo 36, da lei 11.684, de 2008), mas, infelizmente, esses dispositivos foram revogados pela lei 13.415, de 2017, conhecida como a nova reforma do Ensino Médio, o que representou um retrocesso para a formação educacional crítica e reflexiva no país, pois se os seres humanos pensam por natureza, os filósofos, de acordo com a filósofa brasileira Marilena Chaui (2002), são aqueles que ensinam os sujeitos a pensarem sobre o pensado, o que já mostra a importância dessa disciplina para crianças, jovens, adolescentes e adultos. 
Já, no segundo capítulo do livro intitulado "O perfil do aluno adolescente", Velloso (2015) mostrou quem é esse aluno ou essa aluna que não é mais uma criança, mas que também ainda não é um adulto, ou seja, são seres que estão em pleno processo de descoberta e redescoberta. É nessa fase, diz o autor, marcada por conflitos, medos, dúvidas e muitas incertezas que o professor ou a professora de Filosofia, quando conquistam a confiança e o respeito dos alunos, passam a ser requisitados para fornecerem opiniões e conselhos diversos, pois como lembra Velloso (2015, p. 27) "a Filosofia, com certeza, pode servir de instrumento para solucionar quase todas as questões pessoais e sociais as quais incomodam os jovens". Essa passagem é tão verdadeira que o leitor certamente se lembrará da história de Merlí, um professor de Filosofia de meia idade que vive os dramas diários de seus alunos em uma escola no Catalão, na Espanha. A série é exibida na Netflix e mostra a confiança dos alunos depositada em Merlí, que atua não apenas como um difusor de saberes filosóficos em sala de aula, mas, em muitas situações, como um verdadeiro amigo dos seus estudantes.

Após discorrer sobre a importância do pensamento filosófico e apresentar um perfil dos adolescentes, Velloso (2015) escreve sobre "O planejamento de ensino em Filosofia" que é essencial para orientar os docentes em suas práticas pedagógicas. Entretanto, Velloso (2015) chamou à atenção de que o planejamento esboçado por ele não deve ser entendido como uma receita de bolo pronta para ser aplicada em quaisquer circunstâncias. Muito pelo contrário, o autor enfatizou que o docente é o grande maestro que rege a sua turma e, por isso, ele é totalmente livre para refazer o seu percurso todas as vezes que for necessário. Para Velloso (2015), ao planejar uma aula, o professor ou a professora devem perguntar-se: (1) Para que eu vou ensinar? ; (2) O que eu vou ensinar? (3) Para quem eu vou ensinar? (4) Como eu vou ensinar? (5) Como está o processo ensino-aprendizagem? Na perspectiva do referido autor, essas são questões cruciais para quem planeja dar aulas de Filosofia para o Ensino Médio.

Ainda que todas as seções da obra sejam de grande valia para os leitores, considera-se que o quarto capítulo denominado "Métodos ou modos para ensinar 
Filosofia" seja a maior contribuição de Velloso (2015) na abordagem do tema, porque, nesse espaço, ele apresentou quatro vias pelas quais os professores e as professoras podem ensinar Filosofia para adolescentes, a saber: (1) por meio da História da Filosofia; (2) por meio das Áreas da Filosofia; (3) por meio dos Filósofos e suas obras e (4) por meio dos temas ou questões Filosóficas. O interessante desse capítulo é o grau de detalhamento e de riqueza de informações trazidas pelo autor para quem navega pelo mar aberto e desafiante do ensino da filosofia para adolescentes. O capítulo trouxe quatro grandes quadros, nos quais Velloso (2015) mostrou, minuciosamente, como um professor ou uma professora podem trabalhar os conteúdos da Filosofia por cada uma das vias descritas acima. Nesses quadros, ele revelou: (1) objetivo geral e específico da disciplina; (2) os conteúdos que podem ser abordados em sala; (3) as competências e habilidades esperadas dos alunos; (4) o desenvolvimento metodológico para alcançar os resultados esperados; (5) os recursos didáticos e as (5) formas de avaliação.

Outro capítulo consistente desse livro foi escrito sob a denominação de "Atividades didáticas para o ensino de Filosofia", no qual Velloso (2015) apresentou o conjunto de recursos didáticos que podem ser acionados pelos docentes para facilitar o processo de aprendizagem dos estudantes. Nesse capítulo, o autor fez considerações gerais sobre as diversas atividades didáticas, a exemplo da aula expositiva; da confecção de mural; do debate; da visitação à biblioteca e etc. Enfim, Velloso (2015) expôs um painel detalhado e muito bem descrito que permite aos docentes escolherem o recurso didático mais adequado às suas necessidades sem desconsiderar a realidade da escola e de seus alunos.

Se o docente da Filosofia, de modo geral, possui dúvidas sobre o quê e como ensinar conteúdos filosóficos para seus alunos é certo que essas dificuldades, de acordo com Velloso (2015, p. 105), não se resumem a esses aspectos. Para o referido autor, "uma das maiores dificuldades, sobretudo do professor iniciante, é avaliar o seu aluno. A verdade é que estes profissionais ainda não sabem avaliar". Nesse sentido, Velloso (2015) aconselha os seus colegas a pensarem e a praticarem uma avaliação justa e equilibrada, pois ao avaliar um estudante, diz o autor, um professor deve perguntar-se: 
(1) O que estou avaliando no meu aluno? (2) Quais são os critérios de minha avaliação? (3) O que deve ser retido pelo meu aluno?

No último capítulo do livro, intitulado "A relação com a comunidade escolar", Velloso (2015) argumenta que o sucesso do trabalho do Filósofo no Ensino Médio está relacionado ao seu bom relacionamento com a comunidade escolar: (1) equipe administrativa; (2) funcionários; (3) equipe pedagógica; (4) responsáveis e (5) alunos. Além da necessidade de cultivar boas relações como esses atores do processo educacional, Velloso (2015) disse que o professor ou a professora de Filosofia devem estar atentos para o cuidado de si, isto é, eles precisam entender que não há desenvolvimento profissional desarticulado de desenvolvimento pessoal e, por isso, o autor recomenda aos seus colegas que esses meditem sobre o seu fazer pedagógico e busquem qualificação continuada.

Todavia, Velloso (2015) mostrou-se muito cuidadoso ao não indicar aos seus colegas apenas melhorias de desempenho profissional, o que poderia levá-los à exaustão e ao esgotamento à moda da sociedade do cansaço de Byung-Chul Han (2017, p. 99), na qual o sujeito "concorre consigo mesmo e, sob uma coação destrutiva, se vê forçado a superar constantemente a si próprio", mas, pelo contrário, orientou que cada professor e cada professora, na sua mais absoluta singularidade, sejam capazes de proporcionarem-se lazer, descanso, divertimento e, sobretudo, convívio social com familiares e amigos.

Por fim, Lecionando Filosofia para Adolescentes é, de fato, uma bússola que orienta os professores e as professoras a navegarem pelo desafiante oceano filosófico habitado não por criaturas marinhas completamente desconhecidas, mas por seres humanos dotados de muitas dúvidas, incertezas, medos e silêncios e que podem encontrar na Filosofia uma aliada fundamental para aliviar as suas dores de mundo.

\section{Referências}

BOURDIEU, Pierre. Os usos sociais da ciência: por uma sociologia clínica do campo científico. São Paulo: Editora UNESP, 2004. 
CHAUÍ, Marilena. Convite à Filosofia. 12. ed. São Paulo: Ática, 2002.

HAN, Byung-Chul. Sociedade do cansaço. 2.ed; ampl. Petrópolis: Vozes, 2017.

SARTRE, Jean-Paul. O existencialismo é um humanismo. 4. ed. Petrópolis: Vozes, 2014.

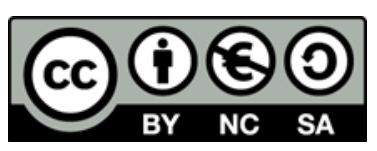

This work is licensed under a Creative Commons Attribution-NonCommercial 4.0 International (CC BYNC 4.0) 